\title{
Geoelectrical mapping of the Soil and Groundwater Contaminated Site: Case Study from Taiwan
}

\author{
Hsin-Chang, LiuChih-PingLin \\ Natural Hazard Prevention and Water Environment \\ Research Center \\ National Chiao Tung University \\ Hsinchu, Taiwan
}

\author{
Chieh-Hou Yang, Tzu-Ping Wang \\ Earth Sciences and Graduate Institute of Geophysics \\ National Central University \\ Taoyuan, Taiwan
}

\begin{abstract}
In recent years, geophysical technology has been widely used in soil and groundwater investigation and remediation of contaminated sites assessments in Taiwan, such technology can securely work in either small or large sampler areas, and collect data from the traditional one-dimensional data to two-dimensional and three-dimensional data. In other words, geophysical technology helps provide more information to assist the data interpretation, and improves the overall effectiveness of soil and groundwater contamination surveys.

Electrical Resistivity Tomography (ERT) is one of useful geophysical technology to the soil and groundwater contaminated sites. By estimating the groundwater flow direction and distribution of contaminations, we could establish monitoring or sampling wells in potential pollution areas. ERT survey could delineate the contaminated areas with high concentrations in relatively simple sites. Even in the seriously DNAPL leakage cases, it is possible to directly detect the DNAPL pool.

In this study, we presented the investigation outcomes of electrical resistivity tomography (ERT) and ground-penetrating radar (GPR) at the DNAPLs-impacted site. Evaluation of ERT/GPR technique deployment in detecting buried DNAPLs and assessment of remediation efforts are also discussed.

Results indicated zones with anomalously high resistivity to be associated with contaminated DNAPLs presence. Resistivity maps clearly outlined the
\end{abstract}

subsurface distribution and the possible migration path of DNAPLs.

Keywords—case study;ERT;DNAPL

\section{I.INTRODUCTION}

Recently, non-invasive technologies such as geophysical technology have been introduced to provide information regarding the "plane and space" of pollution in subsurface by integrating limited boreholes data. The most commonly used geophysical technologies are ground-penetrating radar method (GPR) and electrical resistivity tomography (ERT, also called resistivity imaging profiling, RIP). For pollution investigation, both methods have their limitations in presence of interferences such as building structure or heavy pavement.
Electrical resistivity tomography (ERT) surveying is a popular geophysical exploration technique because of its simple physical principle and efficient data acquisition. Traditional resistivity measurements are carried out on the earth's surface with a specified array in order to obtain apparent-resistivity sounding curves, apparent-resistivity profiling data or apparent resistivity pseudo-sections. All of which qualitatively reflects the vertical or horizontal variations in subsurface resistivity. This technique is widely used in groundwater field, civil engineering, and environmental investigations. In the last decade, there have been great improvements in computerized data acquisition systems and 2D and 3D inversion software. Hence, resistivity imaging or resistivity tomography has become an increasingly attractive exploration technique. Many geophysicists have shown that it is possible to reconstruct an accurate resistivity image of the subsurface using a large number of measured data (with enough spatial samples and coverage) and employing $2 \mathrm{D}$ or $3 \mathrm{D}$ inversion schemes.

The typical high electrical resistivity properties of DNAPLs are useful for DNAPL investigation using geoelectrical methods ${ }^{[4][6][11][12][13]}$. The ERT method provides an effective method for characterizing and monitoring contaminant DNAPL plume in the soil and groundwater. Using ERT technique helped us to outline a leaking of DNAPLs from a waste disposal site ${ }^{[14]}$. The electrical contrast between DNAPL and host rock may allow a contaminant target to be easily imaged. This fact is important in delineating DNAPL contaminants. In addition, non-invasive geoelectrical methods are relative easy to implement, time efficient, and economical in site assessments. Soil and rock resistivity (or conductivity) measurements have been used in the mining industry for many years, and more recently used to monitor remediation of contaminate plumes ${ }^{[3]}$. The electrical resistivity of most soils and rocks depends on the conduction paths afforded by fluids in the pore spaces. The porosity, saturation, pore fluid salinity, and clay content determine resistivity. Because the dissolved 
solids in groundwater influence resistivity, mapping it may be the only direct detection method for high concentrations of contaminants that form ionic species.

Ground penetrating radar (GPR) has been used for over thirty years at chemical and nuclear waste disposal sites as a noninvasive technique for site characterization ${ }^{[5][9]}$. Standard GPR surveys are conducted from the surface of the ground providing geotechnical information and underground or unknown pipes or sump from the surface to depths of 1 to 10 $\mathrm{m}$, depending on GPR frequency of operation and soil conductivity. Changes in the radar waves, which result from the geology and the pore fluids, are used to establish inferences about the geology and the

Case1

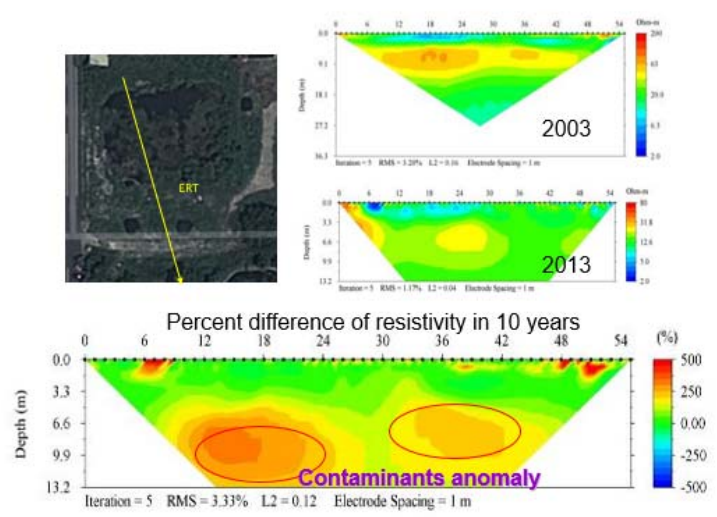

Fig.1 Time-lapse processing is conducted on the data to understand the changes in the underground materials before and after remediation. Timelapse processing is frequently applied during monitoring to determine changes in strata over time

pore fluids. As the radar pulse propagates, it is attenuated due to conductivity and slowed due to the

dielectric constant. Therefore, GPR tomography maps variations in conductivity and velocity from which it is possible to estimate soil characteristics, such as water content, density and contamination.

Detection of organic contaminants, such as DNAPLsplumes, in the subsurface using geophysical methods has been a subject of considerable research interests among geophysicists in recent years ${ }^{[1][2][7][8][10]}$. Their researches have provided valuable information regarding to DNAPLs detection.In this study, we presented the investigation outcomes of electrical resistivity tomography (ERT) and ground-penetrating radar (GPR) at the DNAPLs-impacted site.Evaluation of ERT/GPR technique deployment in detecting buried DNAPLs and assessment of remediation efforts are also discussed.

The study area is in Toufan, northwestern Taiwan. The site encompasses about 11025 sq. m. It is bounded by the Chung Shan Freeway in the south, the Taitai Chemical factory in the north and the Chungs Chemical factory of Toufan in the east. The topography of the site is quite flat. Based on the logs of wells, the subsurface consists of three to four layers. The top layer is a brown or dark soil with a thickness ranging from surface down to a depth of $2.2 \mathrm{~m}$. The second layer is muddy sand layer embedded with gravel and has a depth from surface to $14.2 \mathrm{~m}$. The third layer is a thin gray sandy clay layer with a thickness ranging from 20 to $30 \mathrm{~cm}$. The Case2

(a) Map of the waste disposal site

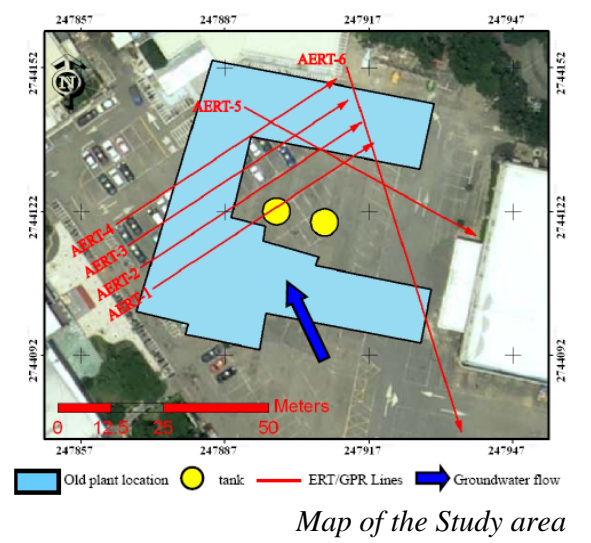

Fig. 2Overview map of the study area showing survey locations

last layer is gray siltstone. The groundwater flows in the southwest with a water level around $4 \mathrm{~m}$. The water table kept a depth of 5.6 to $8.6 \mathrm{~m}$ during pumping and rose to a depth of $2.5 \mathrm{~m}$ after a heavy rain or a long period of precipitation.

Following the successful of previous test surveys, more survey lines were deployed around the pool. The Line was completely on a contaminated subsurface, the inter-electrode spacing was $1 \mathrm{~m}$. Fig. 1 shows the 2003 and 2013 inversion model section of ERT data, it shows that the 2013 resistivity of the model is less than 2003 result except that the resisitivity would be reduce from the EOS, the former is interpreted to be a polluted result and the later is DNAPLs remediation result.

Figure 2 shows the map of the study area, an old waste dump site of abandoned factory located in Hsinchu, Taiwan. In July 2007, the soil and groundwater in the factory was reported to be contaminated by high concentration of dichloromethane, chlorobenzene and other hazardous solvents. The contaminated area was around $10000 \mathrm{~m}^{2}$. No remediation was performed until the Environmental Protection Agency (EPA) of Hsinchu ordered the company to remediate the site in 2008. This included continuous pumping and treatment on 
contaminated groundwater from wells. The DNAPLs existed for a long time and no records of previous

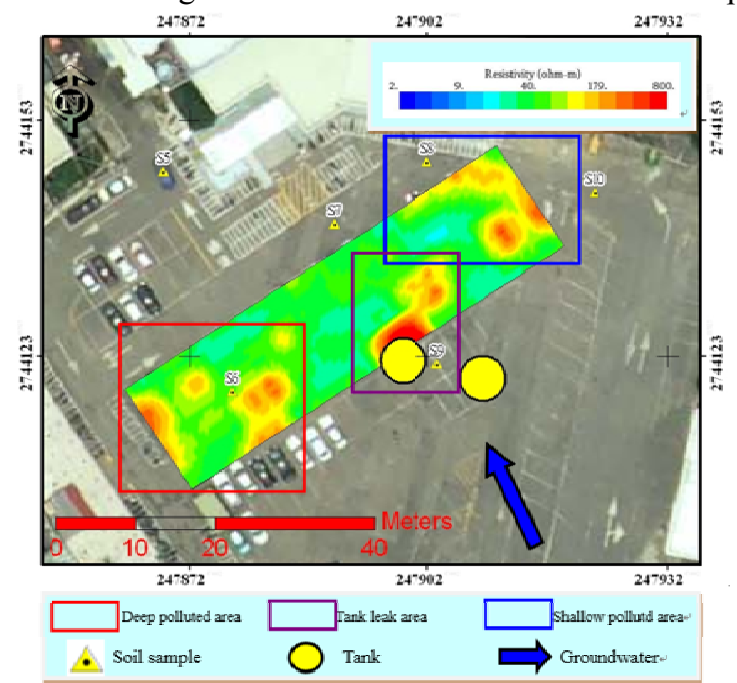

Fig. 3Resistivity maps for $1.5 \mathrm{~m}$ depth

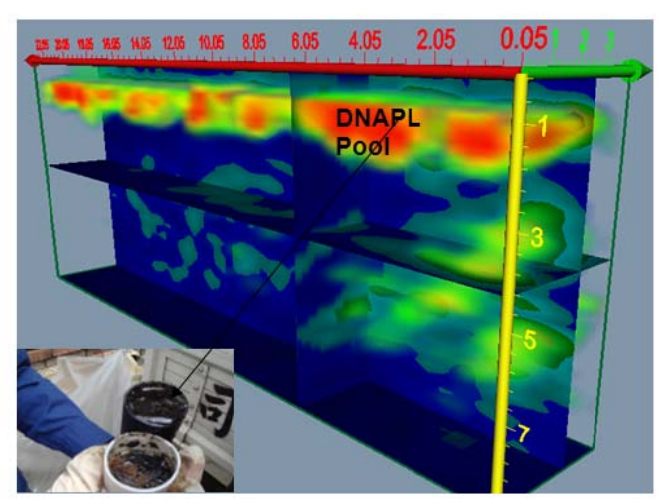

Fig. 4GPR maps for different depth

operation were available. Therefore, significant quantity of DNAPLs remained in the subsurface and infiltrated downwards from the topsoil to lower bedding of fine sand embedded with gravel and siltstone.

This ERT-detected anomaly confirmed the elliptical shallow anomaly (Fig. 3) detected by the GPR survey (Fig. 4). Areas which are measured high resistance using the ERT method have better stratum permeability than other areas and it will enhance plumes to flow to those areas. Also, areas with high resistance may display contamination signals. The resistivity value of high-resistance areas on each measure line is between $10 \sim 800 \Omega-\mathrm{m}$. The resistivity value changed because weathering influenced the oil quality. Areas with LNAPL pollution can be defined according to the results of geophysics ERT/GPR and the soil sampling results of studied areas. The first place is colored purple. Oil contamination areas are from the surface to the depth of 6 meters underground. The contamination is relatively deep. We judged that it was caused by leaks during the manufacturing process in the early years. In accordance with the resistivity value of oil, we judged that the contamination happened many years ago. The second oil contamination place distributes in the blue section in front of the pool. The contamination is also relatively deep. Its range is between $1 \sim 5$ meters underground. The source of contamination was the leaking storage tanks. The third contamination place is located on the southeast corner of the pool. The contamination distributes over $0.75 \sim 2$ meters underground (red section). We judged that it was caused by leaks of another process area.

\section{II.CONCLUSION}

ERT time-lapse data processing can be performed to evaluate detailed changes in the properties of materials within strata and whether areas require further remediation. Effectively employing geophysical exploration techniques to investigate and remediate contaminated sites is beneficial in regard to time, cost, and results. Comparison of the detection results before and after remediation verified that the remediation of the site was complete. The application of geophysical exploration techniques were expanded at sites with soil and groundwater pollution from investigations performed before remediation to examining the effectiveness after remediation. However, the implementation of geophysical profile techniques needs to have relevant expertise and experience to ensure the data quality in order to obtain solid and trustworthy results. No matter it is used at fieldwork or data processing in the laboratories.

The ERT/GPR method provides an effective method for characterizing and monitoring contaminant DNAPL plume in the soil and groundwater. ERT/GPR technique assisted in outlining leakage of DNAPLs from a waste disposal site. Although the unequivocal relationship between modeled resistivity and DNAPLs is difficult to be determined, there are some relationship between the high resistivity zone and DNAPLs for this site.

\section{ACKNOWLEDGMENTS}

The study has received economic support from the Environmental Protection Administration, Executive Yuan, Taiwan, R.O.C.. The authors are grateful for the sponsorship from Soil and Groundwater Pollution Remediation Fund Management Board. 


\section{REFERENCE}

[1] Brewster, M.L., and Annan, A.P., 1994, Ground-penetrating radar monitoring of a controlled DNAPL release: $2000 \mathrm{MHz}$ radar: 59, 1211-1221.

[2] Brewster, M.L., Annan, A.P., Greenhouse, J.P., Kueper, B.N., Olhoeft, Redman, J.D., and Sander, K.A., 1995, Observed migration of a controlled DNAPL release by geophysical methods: Groundwater, 33, 6, 977-987.

[3] De Ryck, S.M., Redman, J.D., and Annan, A.P., 1993, Geophysical monitoring of a controlled Kerosene spill. Proceedings, Symp. on the App. of Geophys. To Eng. and Envir. Prob., 5-20.

[4] Gajdos, V. and Kral, V., 1995. Influence of hydrocarbon pollution to soil conductivity. Proceedings, Symp. on the App. of Geophys. to Eng. and Envir. Prob., 785-789.

[5] Li, Y. and Oldenburg, D.W., 1992, Approximate inverse mapping in DC resistivity problems, Geophysical Journal International 109, 343-362.

[6] Monier-Williams, M., 1995. Properties of light non-aqueous phase liquids and detection using commonly applied shallow sensing geophysical techniques. Proceedings, Symp. on the App. of Geophys. to Eng. and Envir. Prob., 1-13.

[7] Pankow, J.F., Feenstra, S., Cherry, J.A and Ryan, M.C., 1996, Dense chlorinated solvents in groundwater, background and history of the problem in Dense Chlorinated solvents and other DNAPLs in Groundwater, History, Behavior, and Remediation, Pankow, J.F., Cherry, J.A., eds, Waterloo Press, Portland, OR, United States, 1996, p.1-52.

[8] Redman, J.D., Kueper, B.H., and Annan, A.P., 1991, Dielectric stratigraphy of a DNAPL spill and implications for detection with ground penetrating radar: Groundwater Water Management n. 5, Proc. Of the Fifth National Outdoor Action Conference on Aquifer Restoration, Groundwater Water Monitoring and Geophysical Methods, May 13-16, Las Vegas, NV, p. 1017-1030.

[9] Sander, K. A., Olhoeft, G.R., and Lucius, J.E., 1992, Surface and borehole radar monitoring of a DNAPL spill in 3D versus frequency, look angle and time: Proc. Of the Symposium on the Application of Geophysics to Engineering and Environmental Problems, R.S., Bell, ed., April 26-29, 1992, p.455-469.

[10] Schneider, G.W., de Ryck, S.M., and Ferre, P.A., 1993. The application of automated high resolution D.C. resistivity in monitoring hydrogeological field experiments. Proceedings of the Symposium on the Application of Geophysics to Engineering and Environmental Problems. 145-162.

[11] Sauck, W.A., and McNeil, J., 1994. Some problems associated with GPR detection of hydrocarbon plume (abs.). Fifth International Conf. On Ground Penetrating Radar, 34-34.

[12] Sauck, W.A., 1998. A conceptual model for the geoelectrical response of LNAPL plumes in granular sediments. Proceedings, Symp. on the App. of Geophys. To Eng. and Envir. Prob., 805817.

[13] Sauck, W.A., Atekwana, E. A., and Nash, M. S., 1998. High conductivities associated with an LNAPL plume imaged by integrated geophysical techniques. JEEG, 2, 203-212.
[14] Yang, C.H., C.Y. Yu, S.W. Su, 2007, High resistivities associated with a newly formed Lnapl plume imaged by geoelectric techniques- a case study. Journal of the chese Institute of Engineers, 30, 53-62. 